\title{
Regeneration of Gastric Mucosa in Rats ${ }^{1,2}$
}

\author{
SAMUEL FRANKLIN TOWNSEND ${ }^{3,4}$ \\ Department of Anatomy, The University of Michigan Medical School, \\ Ann Arbor, Michigan
}

Since Bensley's (1898) classical description of the specialized cell types in the gastric mucosal epithelium much uncertainty has existed concerning their life history. Grant ('45), Stevens and Leblond ('53), Hunt ('57) and Messier ('60) observed that both surface and mucous neck cells arise from the proliferation of cells in the neck region of the fundic gland and are sloughed off, the mucous neck cells at their site of origin and the surface cells after moving to the surface of the mucosa. Hunt ('57) and Grant ('45) concluded that other cell types in the glands are also lost. Harvey ('07), Ferguson ('28), and Hunt ('58) implied that parietal and chief cells are replaced by transformation from mucous neck cells but Stevens and Leblond ('53) and Messier ('60) denied the loss and replacement of these cell types.

In order to acquire more precise information concerning the origin of the various cell types in fundic glands, numerous investigators have studied their re-appearance in gastric mucosa following surgical or thermal injury to it (Harvey, '07; Ferguson, '28; Gunter, '50; Williams, '53; Hunt, '58; Finckh and Milton, '60). These investigations revealed that (a) the first epithelial cells growing back into an injured area contain mucus and, at least in the newly-formed glands, come to resemble mucous neck cells except for their shape and nuclear structure; and (b) the newlyformed chief and parietal cells seem to arise from these mucus-containing cells. However, conclusive evidence for direct transformation of mucous cells to chief and parietal cells is lacking as is also information concerning the origin of argentophilic cells. Until such evidence is available the sources of these cells cannot be considered proven. Much of the difficulty in visualizing these transformations has arisen from the lack of techniques ade- quate for the demonstration of transitional forms.

The objective of this study was to secure cytological evidence concerning the cellular origin of the chief, parietal and argentophilic cells as they arise in regenerating fundic stomach, utilizing newly modified staining techniques.

\section{MATERIALS AND METHODS}

Young adult female rats of the SpragueDawley strain were used. They were maintained in individual cages and were given water ad libitum throughout the experiment. All rats were fed a diet consisting of Purina Laboratory Chow supplemented weekly with fresh citrus fruit, vegetables and cod liver oil.

Seventy-two rats were utilized, their mean body weight being $162 \pm$ standard deviation of $22 \mathrm{gm}$ before the lesion was placed in the stomach and $199 \pm 40 \mathrm{gm}$ at the time of sacrifice. In placement of the lesion, the stomach was exteriorized and a slit $6 \mathrm{~mm}$ in length was made in the forestomach while the animal was under sodium amytal anesthesia. The glandular mucosa was everted through this slit and stretched to smoothness over a blunt rod which was attached to the operating table. A circular piece of gastric mucosa $6 \mathrm{~mm}$ in diameter was removed from the glandular

\footnotetext{
${ }^{1}$ Supported in part by research grants to Dr. Burton L. Baker from the National Institutes of Health, Public Health Service (A-131 C7, A-2841 C1) and the Upjohn Company.

2 Based on a dissertation submitted in partial fulfilment of the requirements for the Doctor of Philosophy degree.

3 This investigation was carried out during the tenure of a Predoctoral Fellowship from the $\mathrm{Na}$ tional Cancer Institute, United States Public Health Service. Deep appreciation is extended to Dr. Burton L. Baker for his direction of this investigation.

4 Present address: Department of Biology, Kalamazoo College, Kalamazoo, Michigan.
} 
stomach on the greater curvature and two to three millimeters inferior to the horizontal ridge. In doing this a skin punch $6 \mathrm{~mm}$ in diameter was applied to the stretched mucosa and an outline cut was made. With fine forceps one edge of the mucosa was lifted and the points of a pair of iridectomy scissors were slipped under the mucosa into the submucosa. This maneuver separated the mucosa from the submucosa and with the forceps the piece of mucosa was removed. The operated area was examined to make certain that all of the mucosa was excised. Following inversion of the glandular stomach, the incision in the forestomach was sutured. The time allowed for regeneration after excision of the mucosa and the number of rats used at each period were as follows: 4 hours, 2; 12 hours, 1; 1 day, 2; 36 hours, $2 ; 2$ days, $2 ; 4$ days, $2 ; 5$ days, $1 ; 6$ days, 2 ; 7 days, $1 ; 9$ days, $2 ; 10$ days, $8 ; 11$ days, $3 ; 12$ days, $1 ; 14$ days, $1 ; 15$ days, $6 ; 20$ days, $9 ; 21$ days, 1 ; 25 days, $2 ; 28$ days, 2 ; 30 days, 9 ; 35 days, $4 ; 41$ days, $2 ; 42$ days, 2 ; 49 days, 1 ; 56 days, 2 ; 63 days, $1 ; 70$ days, 1 .

Histological and histochemical techniques. Following killing of the rat by a blow on the head, the esophageal and duodenal ends of the stomach were ligated and $4 \mathrm{cc}$ of either Zenkex-formol, Regaud's fluid or formalin-acetic acid-alcohol (FAA) fixative were injected into it; subsequently the stomach was removed and placed in a bottle containing the fixative. This procedure stretched the stomach moderately and facilitated fixation. Six to 8 hours later the stomach was opened, the lesion area was removed and fixation continued. The stomachs of 5 rats were stretched over corks after being opened along the lesser curvature. The lesion area was then removed, frozen and sectioned at $8 \mu$ in a Cryostat. These sections were mounted on slides without albumen and incubated for 10 minutes at $37^{\circ} \mathrm{C}$ for the demonstration of succinic dehydrogenase (Nachlas et al., '57). Pieces of stomach that were fixed in Zenker-formol for 24 hours and Regaud's fluid for 4 or 12 days were treated with $3 \% \mathrm{~K}_{2} \mathrm{Cr}_{2} \mathrm{O}_{7}$ for three days, dehydrated and embedded in celloidin and Tissuemat. They were sectioned at 2 to $4 \mu$. Pieces fixed in FAA for 48 hours were dehydrated, cleared in carbon disulfide and embedded is Tissuemat. They were sectioned at 3 or $4 \mu$.

For the demonstration of mitochondria, sections of the stomach fixed in Regaud's fluid were stained with the Severinghaus and Thompson ('39) Altmann-Masson procedure. The colloidal iron and periodic acid-Schiff technique of Mowry ('58) was used on sections fixed in Regaud's fluid, Zenker-formol or FAA for the demonstration of glycogen, acidic mucopolysaccharides and other carbohydrate-containing proteins and combined with $1 \%$ Bismarck brown in $1 \%$ acetic acid for nucleic acids. The Hotchkiss (48) periodic acid-Schiff technique (PAS) for glycogen and carbohydrate-containing proteins was used in combination with Bodian protargol (Dawson and Barnett, '44) for argentophilic cells on sections fixed in FAA; with Bowie's stain for pepsinogen granules (Bowie, '36) on sections fixed in Regaud's fluid; and with methylene blue $(0.05 \%$ solution containing $13.5 \%$ acetone and a citric acidphosphate buffer at $\mathrm{pH}$ 5.6) and azure IIeosin (Lillie, '54) for nucleic acids on sections fixed in Zenker-formol, FAA and Regaud's fluid. In order to determine whether or not the PAS-staining material was glycogen, some slides were incubated one hour at $37^{\circ} \mathrm{C}$ in a $1 \%$ solution of a-amylase in a $0.01 \mathrm{M}$ Sorenson phosphate buffer ( $\mathrm{pH} 7.0$ ) before staining. Control slides were incubated in the buffer solution without amylase.

\section{OBSERVATIONS}

\section{General histology}

Four hours after the removal of a piece of mucosa, bleeding had occurred into the lesion and the submucosa for some distance away from the lesion. Microscopic examination verified the complete excision of mucosa and muscularis mucosae leaving the submucosa as the floor of the lesion. The size of the lesion varied considerably due to contraction of the surrounding muscularis mucosae.

The established mucosa $a^{5}$ was normal except for a slight increase in blood cells

5 The term "established mucosa" will be used to indicate the mucosa adjacent to the lesion and "regenerating mucosa" that which is newly formed in the lesion. 
in the lamina propria of some sections immediately adjacent to the lesion.

By the 12th hour after the operation the lesion itself was unchanged while in the established mucosa the glands nearest the edge were tipped towards the lesion but still contained their normal types of cells (fig. 3). The lamina propria was congested with blood for a considerable distance away from the lesion's edge, the degree of congestion being greatest adjacent to the edge (fig. 1). Proximal to the lesion the congestion involved all of the mucosa but distally it was restricted to the superficial lamina propria.

Twenty-four hours after the operation, bleeding had ceased and the lesion and neighboring submucosa contained clotted blood. Continuous with the surface cells of the established mucosa but lying out on the clot was a ledge of epithelial cells which was not composed of normal surface cells (fig. 2). They were oval to columnar in shape, contained round to oval nuclei with prominent nucleoli and their cell membranes were not always distinguishable. The most superficial cells contained PAS-positive mucus apically; the deeper cells lacked mucus and close to the established mucosa a few flattened parietal cells were observed in the ledge.

Congestion of the lamina propria of the established mucosa had increased and in some sections was so extensive that the glands were widely separated. Many of the epithelial cells of these glands were flattened but could still be distinguished as to type (fig. 12). The chief cells were smaller, exhibited less cytoplasmic basophilia and contained fewer pepsinogen granules; their nuclei and nucleoli were prominent. The parietal cells were small but more normal in appearance than the chief cells. Mitotic figures were prevalent in the established mucosa adjacent to the lesion which agrees with the observations of Hunt ('58) who showed that at this time the mitotic rate of foveolar and surface cells adjacent to the lesion was increased over that of the mucosa some distance away from the lesion.

Thirty-six hours after the operation the epithelial ledge had changed in form and extended further out onto the lesion. The ledge was composed of flattened cells with spindle-shaped nuclei which contained

\section{EFFECTS OF THE OPERATION ON THE MUCOSA BORDERING THE LESION}

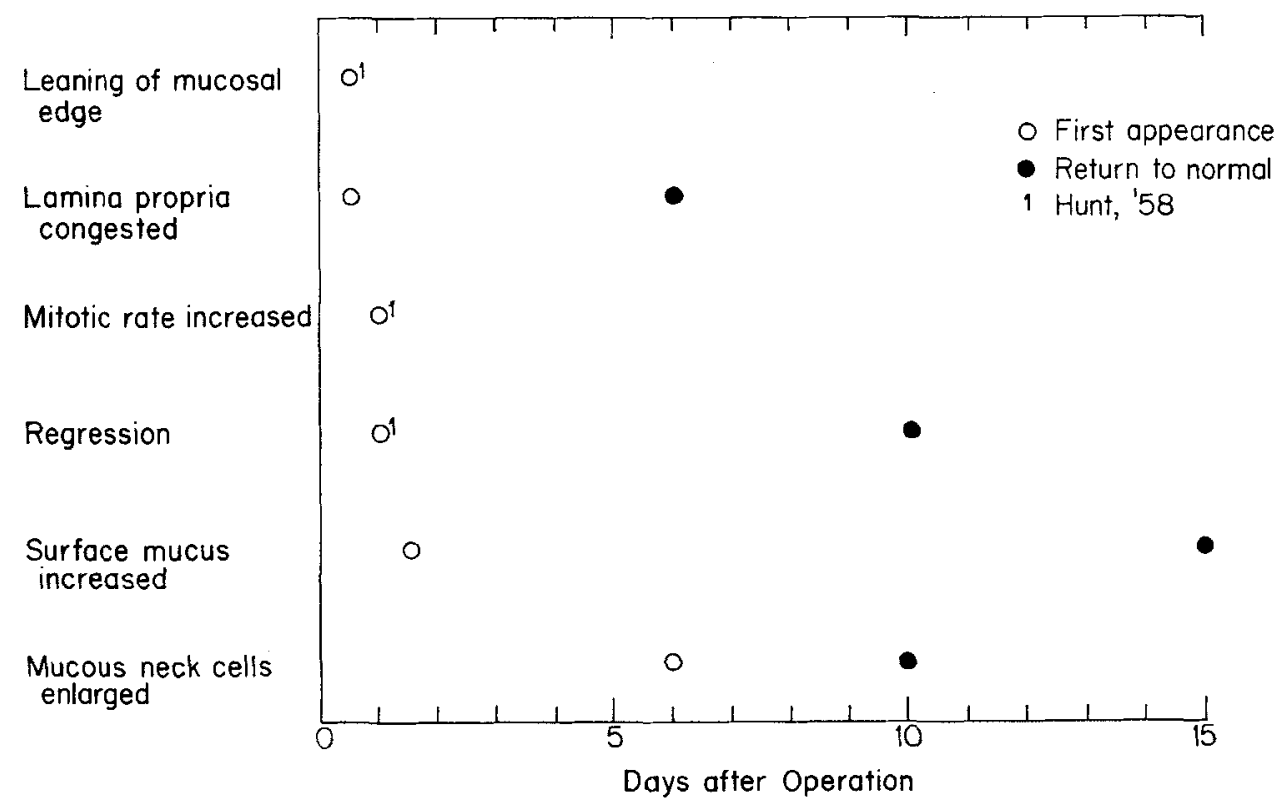

Figure 1 
TIMING OF REGENERATIVE CHANGES

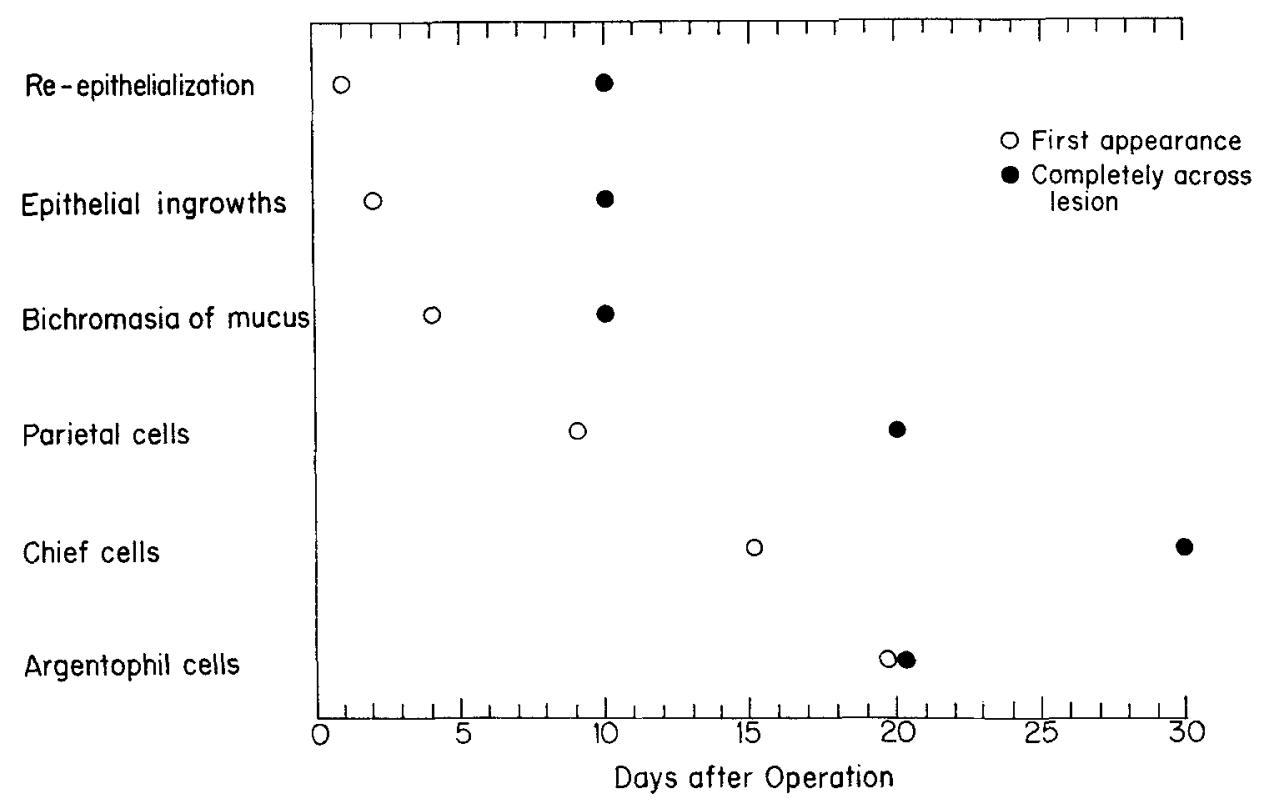

Figure 2

prominent nucleoli (fig. 9). The ledge varied from one to about three cell layers in thickness. Sparsely distributed mucus continued to be present in the superficial cells.

The proximal one or two glands in the established mucosa showed evidence of regression (fig. 13). They were lined by flat to oval, distinctly basophilic cells with prominent nuclei and nucleoli. No chief cells could be identified in these glands but a few flattened, elongated parietal cells were distinguished. Congestion of the lamina propria was often marked in these areas. Mitoses were observed at all levels in these regressed glands. The foveolar cells for some distance from the edge of the lesion were increased in number and in the density of their mucus content. The amount of mucus contained in surface cells was also increased.

At two days the submucosa under the lesion exhibited some evidence of granulation tissue formation. The epithelial ledge had advanced further out on the granulation tissue and had begun to send ingrowths into it. These ingrowths were composed of spindle-shaped cells; some ingrowths exhibited narrow lumina while others were compact.

In the established mucosa the amount of mucus in surface and foveolar cells was increased over that in 36-hour specimens while the congestion of the lamina propria was decreased. The epithelial cells in the glands on the edge of the lesion had enlarged and become more intensely basophilic. Chief cells were indistinguishable in these glands and parietal cells were few in number.

At 4 days granulation tissue filled the lesion and epithelial ingrowths were numerous and more extensive (fig. 10). The cells in the ingrowths closest to the edge of the established mucosa were large and basophilic and contained large nuclei and distinct nucleoli. Some of these cells contained mucus which was stained bichromatically by colloidal iron and PAS, some being purple and some red. The basal ends of the ingrowths were still composed of spindle-shaped cells. The epithelial ledge above the deepest ingrowths was composed of many layers of cells and the cells of the free surface were identical to surface and foveolar epithelial cells. 
In the regressed glands at the edge of the lesion, the mucous neck cells were increased in size and number. The foveolar cells penetrated deeper into the lamina propria and the basophilic cells that lined the glands below the level of mucous neck cells also contained mucus scattered throughout their cytoplasm; it was most concentrated in the apical region (fig. 14). Mitotic figures were prevalent in these basophilic cells.

In the lesion area on the 6th day the epithelial ingrowths from the ledge were deep and consisted of large basophilic cells which contained mucus (fig. 17). The cells lining the upper portion of the ingrowths were similar in staining characteristics to surface and foveolar cells while the mucus in those in the basal half was stained bichromatically by colloidal iron and PAS as were the mucous neck cells in the normal mucosa. The mucus in some cells was entirely purple and in others red, or both reactions were seen in the same cell. These ingrowths could be classified as glands or foveolae on the basis of this staining reaction. The leading portion of the ledge was composed of tall columnar cells which contained densely packed mucus in their apices and scattered granules throughout their cytoplasm (fig. 11).

The most striking feature of the established mucosa at the 6th day was the continued increase in surface and foveolar mucus (fig. 4). The enlarged foveolar cells extended one-half the distance to the muscularis mucosae at the edge of the lesion but more distally approximated normality in these characteristics. The enlarged $\mathrm{mu}$ cous neck cells (figs. 15 and 16) lined the superficial three-quarters of the glands and chief and parietal cells the basal onefourth, except in the proximal few regressed glands where they were replaced by large basophilic, mucus-containing cells. In the regressed glands, transitional stages between mucous neck cells and chief and parietal cells were observed (fig. 19).

On the 9 th day the lesion was well filled with granulation tissue and the ledge of new growth had covered all but a small area (fig. 5). The epithelial ingrowths had for the most part reached a level that corresponded to that of the muscularis mucosae in the established mucosa. The in- growths all exhibited lumina, many of which were large and irregular in shape. The lining was identical to that found at 6 days except for an occasional parietal cell located basally in the glands closest to the edge of the lesion.

The amount of surface mucus, foveolar depth and size and number of mucous neck cells in the established mucosa were the same as in the 6-day specimen. Regressive changes in two or three glands proximal to the lesion in the established mucosa were no longer evident except for the presence of a few scattered large basophilic mucuscontaning cells amongst the parietal and chief cells.

The lesion was re-covered by epithelium in all but one animal by the 10th day and in all animals sacrificed subsequently (fig. 6 ). The epithelial ingrowths had increased in number and all of them could be subdivided into foveolae and glands. The depth and number of foveolar cells, the size and number of mucous neck cells and the amount of surface mucus in the established mucosa were nearly normal. The glands in the established mucosa immediately adjacent to the lesion were normal in cell content.

Fifteen days after the operation the mucosa bordering the lesion had returned to a normal appearance and the lesion itself had changed little from its condition at $\mathbf{1 0}$ days (fig. 1). The only modifications which occurred after 15 days were a further filling in of the lamina propria by branches of previous epithelial ingrowths and the formation of more of the specialized epithelial cell types. At 70 days the newlyformed mucosa differed from normal mucosa in the following ways; a muscularis mucosae was lacking, the number of specialized epithelial cell types was slightly lower and the mucous membrane was somewhat thinner than is true of normal mucosa.

\section{Cytogenesis of special cell types}

Chief cells. A transformation from cells that contained mucus to chief cells was observed in three locations: between the 6th day and 9th day after the operation in the glands immediately adjacent to the lesion (fig. 19), on the 15th day and throughout the rest of the regeneration period in the 
epithelial ingrowths from the ledge (fig. 8 ), and in glands of the established mucosa regardless of the distance from the lesion (fig. 20). In the regressed glands of the established mucosa the source cell was the usually cuboidal, basophilic cell that contained mucus scattered throughout its cytoplasm. In the established mucosa some distance away from the mucosa that was obviously affected by the operation the source cell was the mucous neck cell of the fundic gland. In the epithelial ingrowths the source cell was the basophilic cell that contained mucus with tinctorial and structural characteristics similar to those of the normal mucous neck cell.

In sections stained with PAS and Bowie's stain for pepsinogen granules the cells in transition exhibited the presence of blue pepsinogen granules encompassed by PASpositive red mucus (figs. 18 and 20). As the Bowie-positive granules, cytoplasmic basophilia, cell size and nuclear size increased, the amount of mucus decreased until it was no longer present. In sections treated with a-amylase this transition was still observed since the enzyme did not remove the mucoprotein. In sections stained with PAS and azure II-eosin the cytoplasm above the nucleus contained mucus along with vacuoles in the transitional forms (fig. 19). These vacuoles were left by failure of the fixative to preserve granules.

Parietal cells. Sections treated for succinic dehydrogenase to reveal mitochondria and those stained with eosin demonstrated the presence of parietal cells in the basal portion of the epithelial ingrowths on the 9th day and the presence of parietal cells in all ingrowths across the lesion by the 20th day after the operation (fig. 7). Parietal cells arose in the same sites and from similar mucus-containing cells as was true for chief cells. This transformation was revealed most clearly in preparations stained with colloidal iron and PAS or with PAS and azure II. One of the most striking early changes was the development of dense cytoplasm around the nucleus (figs. 21 and 22 ). The transition in all locations further involved a loss of cytoplasmic basophilia and mucus, enlargement of the cell, its nucleus and nucleolus, and an increase in the number of mitochondria. The increase in size of the cell, nucleus and nucleolus occurred simultaneously with the decrease in basophilia. The resulting cell was parietal cell-like in all characteristics except the amount of mucus in its apical cytoplasm. This appeared to be pushed out of the cell into the lumen of the gland. With loss of the large mass of mucus from the cell, delicately disposed material in the supranuclear region continued to stain with the colloidal ironPrussian blue reaction and appeared to be associated with the intracellular canaliculi.

Argentophilic cells. Argentophilic cells appeared in the regenerating mucosa on the 20th day after the operation (fig. 23). The first ones appeared in the regenerating area in no spatial pattern and others followed in a random manner. In slides stained with PAS and Bodian protargol no transitional stages were observed between mucous cells and argentophilic cells in either the established mucosa or in the regenerating mucosa.

\section{DISCUSSION}

\section{Factors influencing the timing of regenerative changes}

The time required for general histological repair of the gastric mucosa resembled rather closely that observed by other authors. This is surprising because many variable factors make such a correlation difficult. First, varied methods have been used to injure the mucosa. These procedures include cautery (Williams, '53; Hunt, '58; Skoryna et al., '58), scraping of the mucosa down to basal ends of the fundic glands (Finckh and Milton, '60), suction biopsy (Gunter, '50), ulceration pursuant to pyloric ligation (Shay et al., '45), injury due to gastro-enterostomy (Harvey, '07) and surgical excision of portions of the mucosa (Ferguson, '28; Janowitz et al., '55; Myhre, '56). Secondly, previous studies have been carried out on several different species. Thirdly, within a given experiment, partial closure of the lesion by contracture of surrounding tissue complicated the timing of cellular events.

Finally, the regression of specialized epithelial cell types in glands bordering the lesion to a more nondifferentiated type made extremely difficult the precise identification of old regressed glands as opposed to newly regenerated ones, particularly be- 
tween the 4th and 9th days after placement of the lesion. The positional relationship of the glands to the cut end of the muscularis mucosae helped somewhat in making this determination. However, since the glands of the established mucosa at the edge leaned over onto the lesion by the 12 th hour, some of the value of the muscularis mucosae as a landmark was lost. Somewhat similar regressive changes following injury to the gastric mucosa have been observed by Harvey ('07), Ferguson ('28), Hunt ('58), and Finckh and Milton ('60).

Similarity of regeneration to the processes of embryogenesis. During embryonic development of the fundic mucosa in cat and man all glands first became lined with mucoid cells and subsequently parietal and chief cells appeared in that order (Lim, '22). Kirk ('10) observed a similar order in the appearance of parietal and chief cells but did not find mucus in all of their progenitor cells. Thus, in the regenerating rat mucosa, the formation of ingrowths of mucoid cells from the early epithelial ledge, followed by the successive appearance of parietal and chief cells, duplicates in a general way the events of embryogenesis.

Origin of specialized cell types. All previous workers are agreed that the first cell type to appear in regenerated glands is a mucus-containing cell. Ferguson ('28) and Hunt ('58) identified it as a mucous neck cell. As evidence in support of this identity can be cited the similar structure and staining capacity of the mucoprotein in the two types of cells as revealed by PAS, and the bichromatic properties of the mucoprotein when stained with the colloidal iron-PAS procedure. Also, in sections of the lesion area, mucous neck cells formed a zone through the established mucosa which was continuous with the mucoid cells of the regenerated glands at the edge of the lesion. Finally, by the 30th day and following neoformation of abundant chief and parietal cells in deeper portions of new glands, mucoid cells remained in the superficial portions of the glands and were indistinguishable from mucous neck cells. Suggesting lack of identity of mucoid cells in regenerated glands with mucous neck cells were differences in size and shape of the cell as well as in size and structure of nuclei and nucleoli. Although the identity of the two cell forms is not established, presently available evidence indicates that they are the same.

Harvey ('07), Ferguson ('28) and Hunt ('58) concluded previously that mucuscontaining cells transform into parietal and chief cells. With respect to chief cells; Harvey reported the presence of mucus and zymogenic granules in the same cell. These demonstrations were not achieved contemporaneously but necessitated prior staining of zymogenic granules with neutral gentian followed by extraction of this dye and subsequent staining of mucus with mucihematin. Ferguson ('28) failed to demonstrate zymogenic granules in the dog. In parietal cells at the neck of fundic glands, Harvey ('07, fig. 4) observed that neutral gentian stained large masses of material the nature of which was not established. This material was undoubtedly the mucus demonstrated in my study by staining with PAS and the colloidal iron-Prussian blue reaction. The present study reinforces the conclusion of these authors that mucous cells transform into chief and parietal cells by providing cytologic evidence of the existence of transitional forms. This was accomplished by combining the PAS procedure for mucoprotein with the Bowie technique for pepsinogen granules after fixation in Regaud's fluid followed by post-chromation. Similarly, a combination of PAS, colloidal iron (Mowry, '58) and Bismarck brown provided an excellent demonstration of transitional parietal cells. The combination of PAS and azure II and eosin was helpful in the study of the origin of both chief and parietal cells. The comclusion that mucuscontaining cells may transform into parietal and chief cells stands in contrast to that of Stevens and Leblond ('53), who were unable to find such evidence after staining with PAS and hematoxylin.

The presence of cells which are transitional between two other types does not by itself reveal the direction in which change is occurring. Indeed, Ferguson ('28) concluded that chief, parietal and foveolar cells can change into mucous neck cells; in the present study evidence was obtained for the regression of chief and parietal cells 
into a mucus-containing cell. However, the order of appearance of cell types in the regenerating mucosa and the fact that immature surface mucous cells and mucous neck cells constitute the primary proliferating types in the normal gastric mucosa, make the transformation of mucous neck to chief and parietal cells more likely in the normal situation.

The failure to find transitional forms between mucoid cells and argentophilic cells indicates that the cellular source of argentophilic cells is different from that of the chief and parietal cells. The random pattern of appearance of these cells also sets them apart. In contrast, chief and parietal cells arose first basally in the new glands along the edge of the lesion and then appeared in the new glands farther out in the lesion area. Since mucoid cells were never observed in transition to argentophilic cells only the cells normally found in the connective tissue and in the blood stream are left as probable sources for this cell type.

Turnover of epithelial cells. The present observations bear upon the currently debated problem of cell turnover in the rat stomach. Messier ('60), using $\mathrm{H}^{3}$-thymidine labeling, observed that surface and mucous neck cells undergo turnover but concluded that chief and parietal cells do not. Myhre ('60) and Hunt and Hunt ('61) utilized the same approach and found that labeling did occur deep in the glands of the fundic stomach. The Hunts observed following the administration of $48 / 80$, that the location of labeled cells moved progressively from the neck region to the basal portion of the gland and that the type of cell labeled changed from the mucous neck variety to chief and parietal cells. Therefore, they concluded that mucous neck cells change into chief and parietal cells. My observations support their position.

\section{SUMMARY}

The origin of chief, parietal and argentophilic cells was studied in the regenerating and established gastric mucosa of rats after excision of a circular area of mucosa. In the established mucosa at the edge of the lesion between the first and 4th days the lamina propria was congested with blood, the amount of surface mucus was in- creased, mucous neck cells were enlarged, and the chief and parietal cells had become flattened and apparently transformed into basophilic, mucus-producing cells. Between the 4th and 10th days, the amount of surface mucus remained high, the congestion of the lamina propria decreased, and the chief and parietal cells appeared to arise by direct transformation from mucus-containing cells.

In healing of the lesion an epithelial ledge composed of mucus-containing cells arose at the rim of the lesion from the surface epithelium on the first day. It grew over the denuded submucosa and from it cellular projections extended into the underlying granulation tissue. These ingrowths developed lumina and mucus soon appeared in the constituent cells. The occurrence of transitional cell types was interpreted to indicate that these mucus-containing cells as well as mucous neck cells transform into chief and parietal cells. Argentophilic cells also arose in the regenerating mucosa but transitional stages from mucus-containing cells were not observed.

\section{LITERATURE CITED}

Bensley, R. R. 1898 The structure of the mammalian gastric glands. Quart. J. Micr. Sci., 41: 361-389.

Bowie, D. J. 1936 A method for staining the pepsinogen granules in gastric glands. Anat. Rec., 64: 357-368.

Dawson, A. B., and J. Barnett 1944 Bodian's protargol method applied to other than neurological preparations. Stain Technology, 19: 115-118.

Ferguson, A. N. 1928 A cytological study of the regeneration of gastric glands following the experimental removal of large areas of mucosa. Am. J. Anat., 42: 403-441.

Finckh, E. S., and G. W. Milton 1960 Regeneration of gastric mucosa from differentiated cells. J. Path. Bact., 80: 143-145.

Grant, R. 1945 Rate of replacement of the surface epithelial cells of the gastric mucosa. Anat. Rec., 91: 175-185.

Gunter, G. S. 1950 A histological investigation of the healing of acute gastric ulceration in the cat. Gastroenter., 15: 708-717.

Harvey, B. C. H. 1907 A study of the structure of the gastric glands of the $\mathrm{dog}$ and of the changes they undergo after gastroenterostomy and occlusion of the pylorus. Am. J. Anat., 6: 207-243.

Hotchkiss, R. D. 1948 A microchemical reaction resulting in the staining of polysaccharide structures in fixed tissue preparations. Arch. Biochem., 16: 131-141. 
Hunt, T. E. 1957 Mitotic activity in the gastric mucosa of the rat after fasting and refeeding. Anat. Rec., 127: 539-550.

1958 Regeneration of the gastric mucosa in the rat. Ibid., 131: 193-212.

Hunt, T. E., and E. A. Hunt 1961 Thymidine$\mathrm{H}^{3}$ radioautographs of the gastric mucosa of the rat after stimulation with compound $48 / 80$. Ibid., $139: 240-241$.

Janowitz, H. D., V. A. Weinstein and F. Hollander 1955 Effect of cortisone on healing of experimental gastric ulcer. Fed. Proc., 14: 79.

Kirk, E. G. 1910 On the histogenesis of gastric glands. Am. J. Anat., 10: 473-519.

Lillie, R. D. 1954 Histopathologic Technic and Practical Histochemistry. The Blakiston Division, McGraw-Hill Co., Inc., New York.

Lim, R. K. S. 1922 The gastric mucosa, Quart. J. Micr. Sci., 66: 187-212.

Messier, B. 1960 Radioautographic evidence for the renewal of the mucous cells in the gastric mucosa of the rat. Anat. Rec., 136: 242.

Mowry, R. W. 1958 Improved procedure for the staining of acidic polysaccharides by Müller's colloidal (hydrous) ferric oxide and its combination with the Feulgen and periodic acidSchiff reactions. Lab. Invest., 7: 566-576.
Myhre, E. 1956 Regeneration of the fundic mucosa in rats; effects of estrone and of castration. A. M. A. Arch. Path., 62: 30-36.

1960 Regeneration of the fundic mu. cosa in rats: V. An autoradiographic study on the effect of cortisone. Ibid., 70: 476-485.

Nachlas, M. M., K. C. Tsou, E. Souza, C. S. Cheng and A. M. Seligman 1957 Cytochemical demonstration of succinic dehydrogenase by the use of a new $p$ nitrophenyl substituted ditetrazole (NBT). J. Histochem. Cytochem., 5: 420-436.

Severinghaus, A. E., and K. W. Thompson 1939 Cytological changes induced in the hypophysis by prolonged administration of pituitary extract. Am. J. Path., 15: 391-412.

Shay, H., S. A. Komarov, S. S. Fels, D. Meranze, M. Gruenstein and H. Siplet 1945 A simple method for the uniform production of gastric ulceration in the rat. Gastroenter, 5: 43-61.

Skoryna, S. C., D. R. Webster and D. S. Kahn 1958 A new method of production of experimental gastric ulcer: The effects of hormonal factors on healing. Ibid., 34: 1-10.

Stevens, C. E., and C. P. Leblond 1953 Renewal of the mucous cells in the gastric mucosa of the rat, Anat. Rec., 115: 231-245.

Williams, A. W. 1953 Observations on the healing of experimental gastric ulcers in small laboratory animals. Brit. J. Surg., 41: 319-326. 
PLATE 1

EXPLANATION OF FIGURES

The sections of gastric mucosa illustrated on this plate were stained with periodic acidSchiff (PAS) and azure II-eosin. A- argentophilic cell, C- chief cell, P-parietal cell, M- mucous neck or mucoid cell, L- epithelial ledge, I- epithelial ingrowth.

3 The mucosa 12 hours after placement of the lesion. Bleeding has occurred into the area of the lesion and the surrounding submucosa. The lamina propria of the established mucosa is congested with blood and the glands adjacent to the lesion have leaned inwards. Fixation in Regaud's fluid. $\times 64$.

4 The mucosa 6 days after surgery. Surface and foveolar mucus is increased in the established mucosa. A ledge of epithelial cells has moved out onto the blood clot and epithelial ingrowths have arisen from the ledge. Fixation in Zenker-formol. $\times 64$.

5 The mucosa 9 days after surgery. The lesion is nearly closed and the epithelial ingrowths are numerous. Granulation tissue has replaced the blood clot. Fixation in Zenker-formol. $\times 56$.

6 The mucosa 10 days after surgery. The Iesion is completely re-epithelialized and epithelial ingrowths have filled in most of the lamina propria. Fixation in FAA. $\times 52$.

7 The mucosa 20 days after surgery. Parietal cells are present throughout the lesion that is now full of epithelial ingrowths which can be subdivided into foveolae and glands. Fixation in FAA. $\times 216$.

8 The mucosa 30 days after surgery. Chief, parietal and mucoid cells are present throughout newly-formed glands. A gland from the center of the lesion is shown. Fixation in Zenker-formol. $\times 336$. 


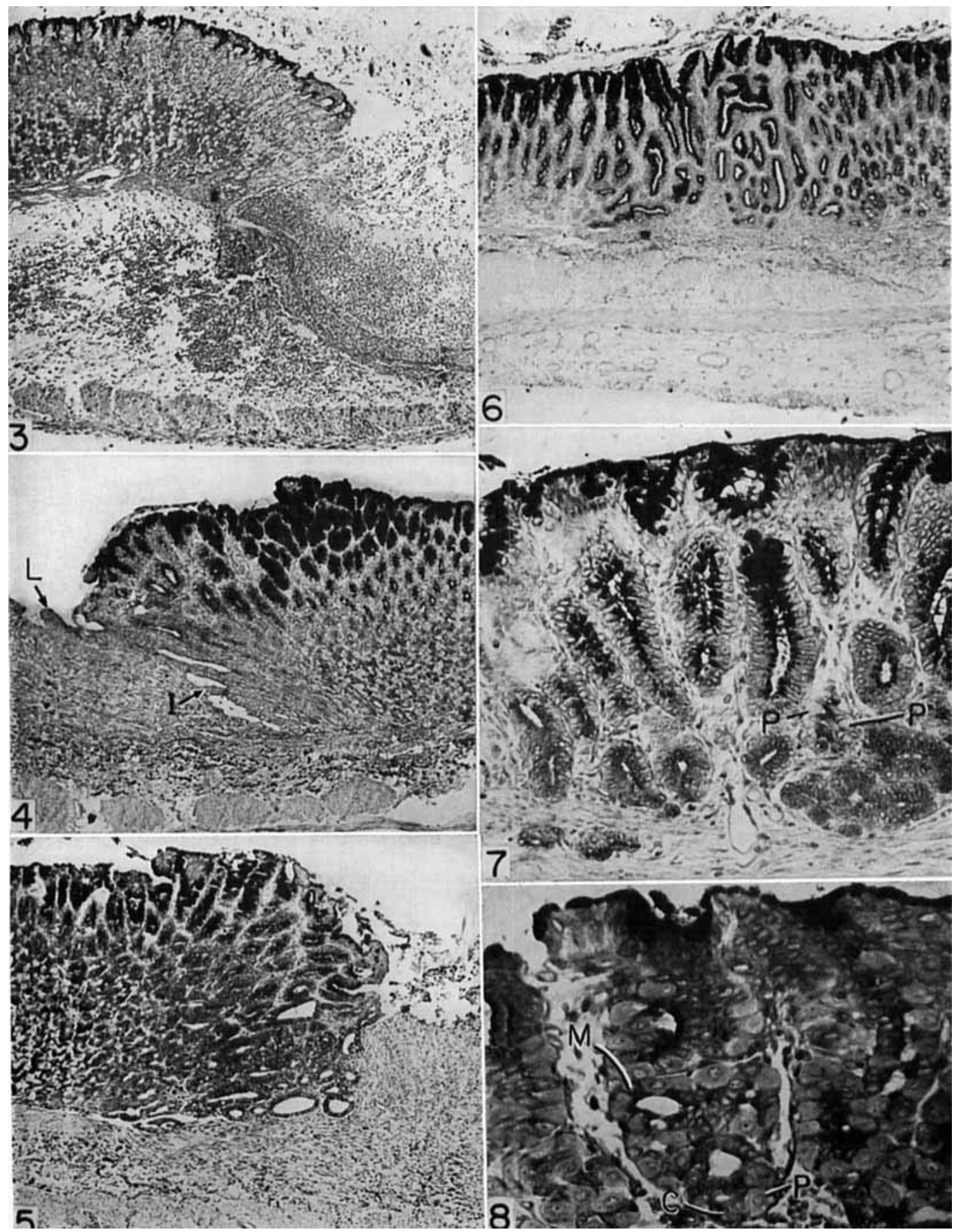




\section{PLATE 2}

EXPLANATION OF FIGURES

The sections of gastric mucosa illustrated on this plate were fixed in Zenker-formol and stained with the PAS-azure II-eosin technique.

9 Early epithelial ledge formation, 36 hours after injury. A thin layer of epithelial cells continuous with the surface epithelium of the established mucosa has moved out onto the blood clot that fills the lesion. $\times 560$.

10 Early epithelial ingrowths, 4 days after surgery. Epithelial ingrowths from the ledge are composed of basophilic cells with large nuclei and prominent nucleoli. Some ingrowths exhibit lumina, others are compact epithelial masses. $\times 360$.

11 The epithelial ledge at 6 days. The leading edge of the ledge of epithelial cells and the formation of new glands are shown. Some of the cells in the new growth are dividing (arrows). $\times 736$.

12 Regression 24 hours after surgery in the established mucosa adjacent to the lesion showing flattened parietal (RP) and chief (RC) cells. Compare RP and RC with more normal parietal $(P)$ and chief $(C)$ cells. $\times 560$.

13 Regression 36 hours after surgery in the established mucosa adjacent to the lesion showing two normal glands (on the left) and several regressing glands (arrows). $\times 560$.

14 Regression 4 days after surgery in the established mucosa adjacent to the lesion showing the extent of the process and the presence of mucus (arrow) in the regressed glands. $\times 96$. 
REGENERATION OF GASTRIC MUCOSA
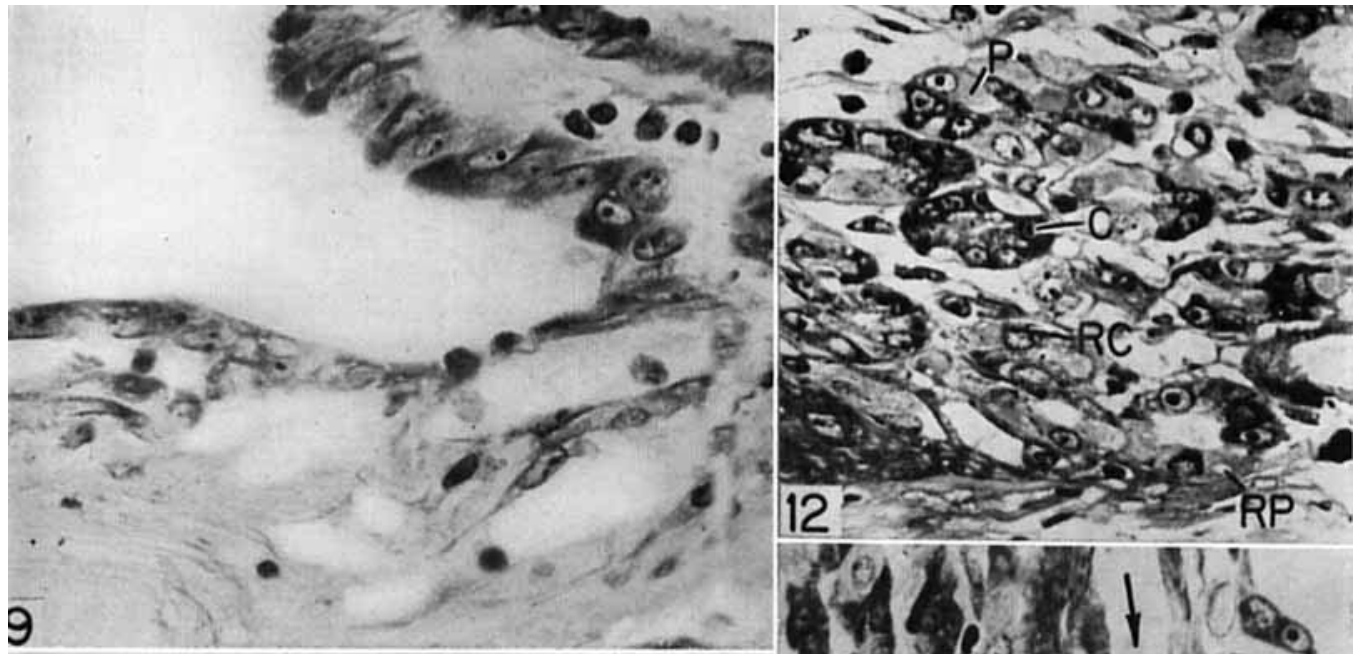

5

3
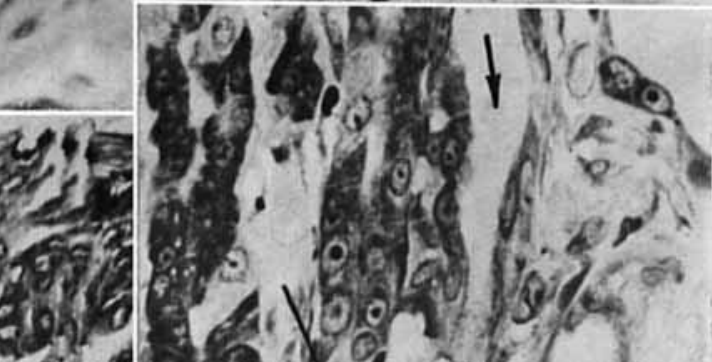

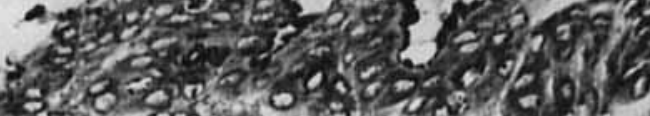

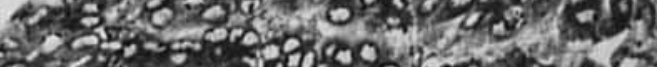

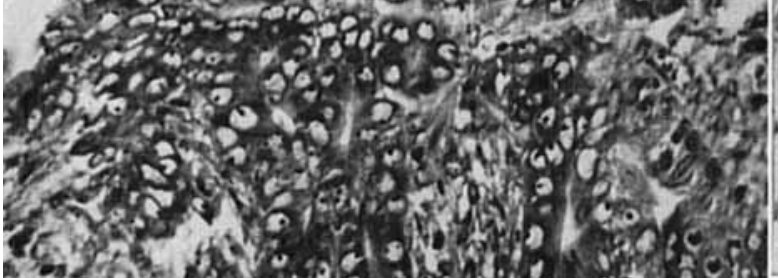

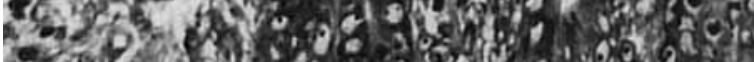

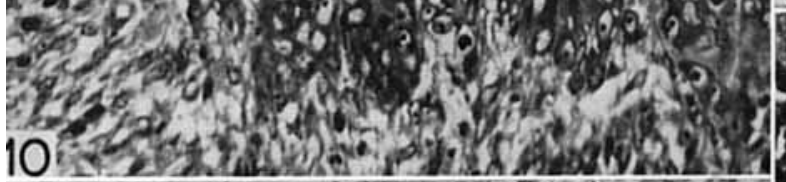
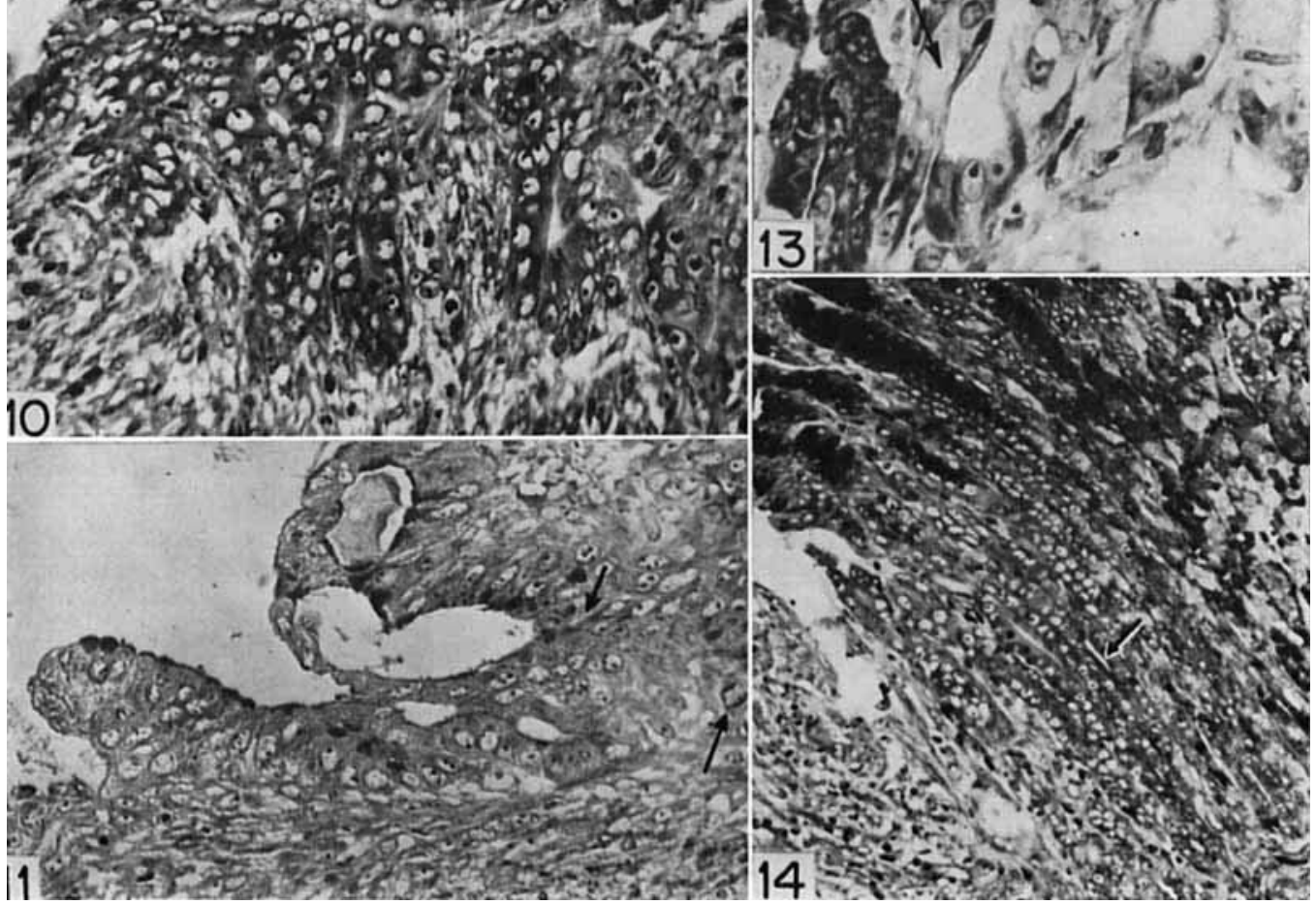


\section{PLATE 3}

\section{EXPLANATION OF FIGURES}

15 Enlarged mucous neck cells in the established mucosa adjacent to the lesion 6 days after injury. Zenker-formol fixation, PAS and azure II-eosin. $\times 1030$.

16 Normal mucous neck cells in the established mucosa some distance away from the lesion 6 days after injury. Zenker-formol fixation, PAS and azure II-eosin. $\times 1030$.

17 Epithelial ingrowth 6 days after surgery. Large basophilic cells which contain mucus and ultimately give rise to other cell types are shown. Zenker-formol fixation, PAS and azure II-eosin. $\times 1030$

18 Chief cell origin in epithelial ingrowth 15 days after injury. At $M$ is a mucoid cell in which the mucus stained with PAS appears gray. At $T$ are transitional cells in which the background mucus stained with PAS is gray but in which pepsinogen granules (black) are also revealed by the Bowie stain. Several other transitional cells are also present. Fixation in Regaud's fluid, PAS and Bowie's stain. $\times 968$.

19 Chief cell restoration in regressed glands of the established mucosa adjacent to the lesion 6 days after surgery, showing chief cells with vacuolated cytoplasm and a small amount of perinuclear basophilia (C), mucoid cells with dark mucus (M), and transitional forms with enlarged nuclei, basophilic cytoplasm, mucus, and vacuoles left by nonpreserved pepsinogen granules. Zenker-formol fixation, PAS and azure II-eosin. $\times 1030$.

20 Chief cell origin in established glands some distance away from the lesion. The evidence for cell metamorphosis is similar to that illustrated in the regenerating niucosa (fig. 18). At $M$ are mucous neck cells, at $T$ transitional cells containing both mucus and Bowie-stained pepsinogen granules and at $C$ and elsewhere, chief cells which no longer show mucus. Fixation in Regaud's fluid, PAS and Bowie's stain. $\times 1030$.

21 Epithelial ingrow mation of mucoid cells to parietal cells. Several cells are illustrated $\left(P_{1-3}\right)$ which basally contain the typical dense cytoplasm of parietal cells and in their apices, masses of mucus of variable size. These cells are regarded as transitional cells. Zenker-formol fixation, colloidal iron and PAS. $\times 968$

22 Parietal cell origin in the established mucosa some distance away from the lesion 15 days after surgery. Illustrated are an early stage $\left(\mathbf{P}_{1}\right)$, a late stage $\left(\mathbf{P}_{2}\right)$ and a mucous neck cell (M). Zenker-formol fixation, colloidal iron and PAS. $\times 968$.

23 An argentophilic cell in an epithelial ingrowth 20 days after surgery. Illustrated are an argentophilic cell (A) and mucoid cells (M). FAA fixation, PAS and protargol. $\times 1030$. 


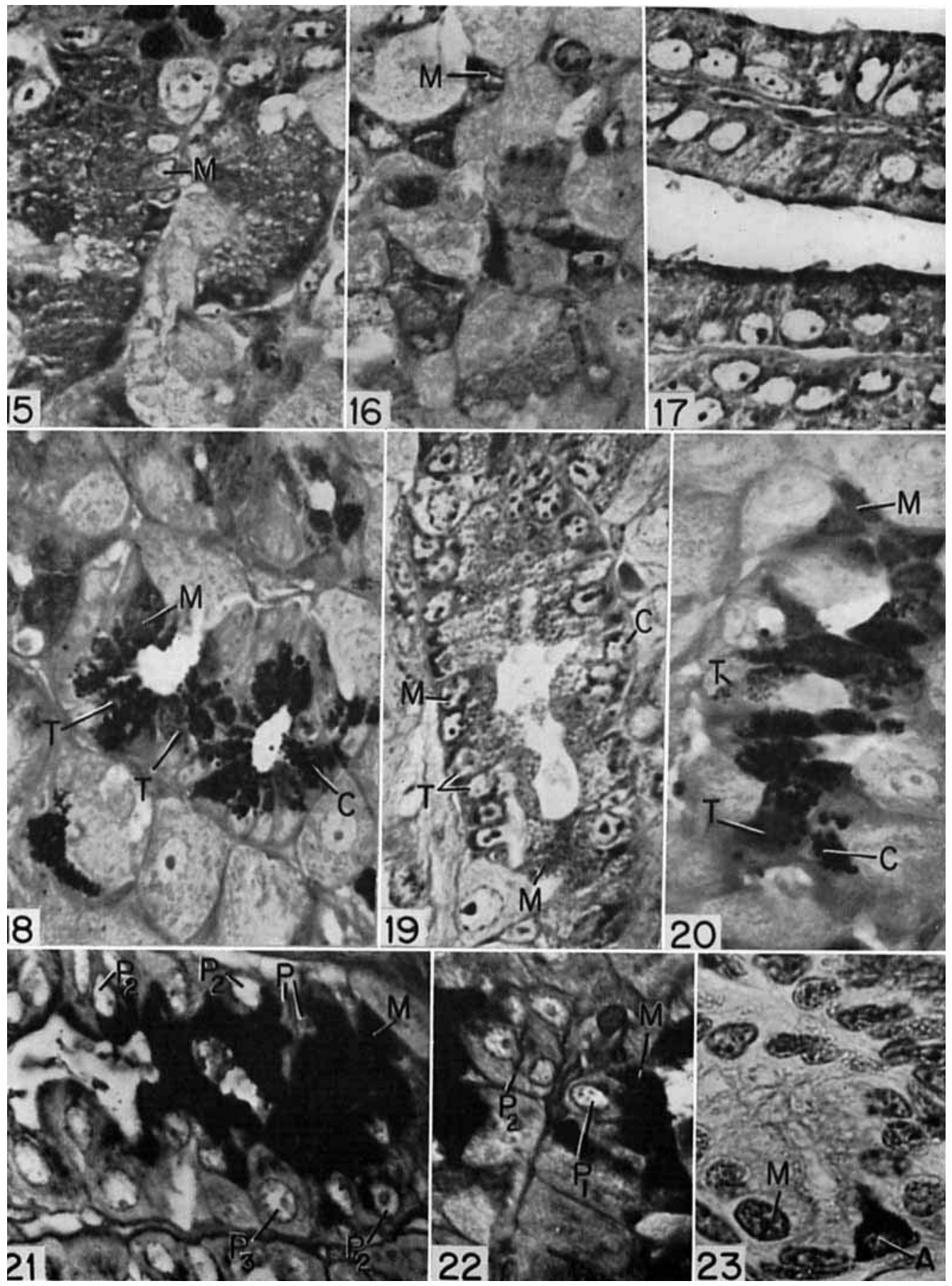

